JURNAL KEBIDANAN

Vol 6, No 3, Juli 2020 : 361-367

\title{
PENGARUH PENDIDIKAN KESEHATAN DENGAN E-MAGAZINE TERHADAP PENGETAHUAN REMAJA PUTRI TENTANG PENCEGAHAN KANKER PAYUDARA
}

\author{
Rani Fitriyani Supriatna ${ }^{1}$, Neneng Martini ${ }^{2}$, Ari Indra Susanti ${ }^{3}$, \\ Dini Saraswati Handayani ${ }^{4}$, Sefita Aryuti Nirmala ${ }^{5}$
1Program Pendidikan Diploma IV Kebidanan Fakultas Kedokteran, Universitas Padjadjaran email: ranifitrianis@gmail.com
2Departemen IImu Kesehatan Masyarakat, Fakultas Kedokteran, Universitas Padjadjaran email: neneng_martini@yahoo.co.id
3Departemen IImu Kesehatan Masyarakat, Fakultas Kedokteran, Universitas Padjadjaran email: ari.indra@unpad.ac.id
${ }^{4}$ Departemen IImu Kesehatan Masyarakat, Fakultas Kedokteran, Universitas Padjadjaran email: d_zsharaswaty@yahoo.com
5Departemen IImu Kesehatan Masyarakat, Fakultas Kedokteran, Universitas Padjadjaran email: sf.nirmala@gmail.com

\begin{abstract}
Background: Breast cancer is the common illness which often happens to womens, in developed or developing countries. West Java Province Health Profile in 2016 was found 912 breast cancer sufferers and one of them is Sumedang with positive breast lump tumors as much as $9.53 \%$. Efforts to prevent breast cancer that can be done is health education regarding breast cancer given to adolescent girls.

Purpose: This research aim to determine the effect of providing health education about breast cancer prevention with e-magazine towards adolescent girls knowledge in SMAN Tanjungsari.

Methods: This research used to a quasi experimental method with an approach pra eksperimental one group pre test-post test design. Sampling using techniques proportional sampling and simple random sampling, samples was 90 adolescent girls in SMAN Tanjungsari. The data is collected by questionnaire. The bivariate data analyzsis is used Paired Sample T-Test with the Statistical Package for Social Science (SPSS).

Results: The results of this research is showed there is an increased adolescent girls knowledge before and after health education with e-magazine $(p=0,009)$ and showed there is an influence from e-magazine to adolescent girls knowledge $(r=0,276)$.

Conclusion: There is an influence of e-magazine to the adolescent girls knowledge in SMAN Tanjungsari.

Suggestion It is better for young women to better understand and pay attention to reproductive health from an early age and can make e-magazine as a reference and learning media to get health information about breast cancer prevention. Educators (teachers) can also work together with health workers and parents in order to provide appropriate health education to young women.
\end{abstract}

Keywords: Adolescent Girl, Breast Cancer, E-Magazine, Health Education, Knowledge.

\section{ABSTRAK}

Latar Belakang: Kanker payudara merupakan kanker yang paling umum terjadi pada wanita, baik di negara maju maupun berkembang. Menurut Profil Kesehatan Provinsi Jawa Barat tahun 2016 terdapat penderita kanker payudara sebanyak 912 orang dan salah satunya Kabupaten Sumedang dengan positif tumor benjolan payudara sebanyak 9,53\%. Upaya pencegahan kanker payudara dapat dilakukan dengan memberikan pendidikan kesehatan mengenai pencegahan kanker payudara pada remaja perempuan.

Tujuan: Tujuan penelitian ini untuk mengetahui pengaruh pemberian pendidikan kesehatan tentang pencegahan kanker payudara dengan e-magazine terhadap pengetahuan remaja putri di SMAN Tanjungsari.

Metode: Penelitian ini menggunakan metode quasi eksperimental dengan pendekatan pra eksperimental one group pre test-post test design. Pengambilan sampel menggunakan teknik proportional sampling dan simple random sampling. Waktu penelitian ini dilaksanakan pada bulan Juli tahun 2019 dan sampel berjumlah 90 remaja putri di SMAN Tanjungsari. Pengumpulan data dilakukan dengan menggunakan kuesioner. Analisis data bivariate menggunakan uji Paired Sample T-Test dengan program Statistical Package for Social Science (SPSS). 
Hasil: Hasil penelitian ini menunjukkan bahwa terdapat peningkatan pengetahuan remaja putri sebelum dan sesudah diberikan pendidikan kesehatan dengan e-magazine $(p=0,009)$ dan terdapat pengaruh dari emagazine terhadap pengetahuan remaja putri $(r=0,276)$.

Kesimpulan: Pada penelitian ini terdapat pengaruh pemberian pendidikan kesehatan tentang pencegahan kanker payudara dengan e-magazine terhadap pengetahuan remaja putri di SMAN Tanjungsari.

Saran Sebaiknya remaja putri dapat lebih memahami dan memperhatikan mengenai kesehatan reproduksi sejak dini serta dapat menjadikan e-magazine sebagai referensi dan media pembelajaran untuk mendapatkan informasi kesehatan mengenai pencegahan kanker payudara. Bagi tenaga pendidik (guru) juga dapat bekerja sama dengan tenaga kesehatan dan orangtua agar dapat memberikan pendidikan kesehatan yang tepat pada remaja putri.

Kata Kunci: Remaja Putri, Kanker Payudara, E-Magazine, Pendidikan Kesehatan, Pengetahuan.

\section{PENDAHULUAN}

Kanker payudara merupakan kanker yang paling umum terjadi pada wanita, baik di negara maju maupun berkembang. Menurut WHO tahun 2013 kejadian kanker meningkat dari 12,7 juta kasus pada tahun 2008 menjadi 14,1 juta kasus pada tahun 2012, dengan jumlah kematian meningkat dari 7,6 juta orang pada tahun 2008 menjadi 8,2 juta pada tahun 2012 (Kementrian Kesehatan RI, 2014).

Menurut data Profil Kesehatan Provinsi Jawa Barat tahun 2016, ditemukan penderita kanker payudara sebanyak 912 orang, 0,013\% dari sasaran wanita usia 30-50 tahun atau $1,42 \%$ dari jumlah yang diperiksa. Data tersebut tersebar di 15 Kabupaten/Kota dan salah satunya yaitu Kabupaten Sumedang dengan positif tumor benjolan payudara sebanyak 9,53\% (Dinas Kesehatan Provinsi Jawa Barat., 2017).

Seiring berkembangnya zaman, jumlah penderita kanker payudara di Indonesia semakin bertambah. Kanker payudara cenderung berdampak pada perempuan yang memasuki usia senja diatas 50 tahun, namun tidak menutup kemungkinan usia kurang dari 50 tahun pun dapat terkena kanker payudara. Saat ini sudah terdapat penderita kanker payudara yang menyerang perempuan berusia muda atau remaja (Sinaga Cf \& Ardayani T, 2016).

Faktor-faktor yang dapat memengaruhi kanker payudara diantaranya adalah faktor genetik atau adanya riwayat kanker payudara dalam keluarga, adanya riwayat kanker payudara dalam keluarga dapat menjadi peluang $50 \%$ seorang anak perempuan menderita kanker payudara. Faktor gaya hidup dan lingkungan juga dapat menjadi pemicu terserangnya kanker payudara, seperti kurangnya mengkonsumi sayur dan buah, tidak berolahraga dan mengkonsumsi alkohol dapat menjadi pemicu pertumbuhan sel kanker payudara (Dinas Kesehatan Provinsi Jawa Barat., 2017).
Menurut penelitian Gusti Ayu tahun 2016, faktor yang dapat memengaruhi kejadian kanker payudara adalah tingkat pengetahuan yang kurang mengenai bagaimana cara mendeteksi dan mengetahui gejala kanker payudara. Maka dari itu banyak penderita kanker payudara yang terlambat untuk melakukan pemeriksaan awal ke pelayanan kesehatan di Indonesia mencapai lebih dari $80 \%$. Hal ini menyebabkan kejadian kanker payudara banyak yang ditemukan dalam keadaan stadium lanjut (Dyanti Gar \& Suariyani Nlp, 2016).

Salah satu upaya untuk meningkatkan pengetahuan mengenai pencegahan kanker payudara adalah dengan memberikan pendidikan kesehatan. Media pendidikan kesehatan yang dapat diberikan salah satunya adalah menggunakan media cetak atau media massa agar menjadi lebih menarik. Menurut kerucut pengalaman Edgar Dale, media pendidikan kesehatan yang mampu meningkatkan kemampuan sasaran dalam mengingat pesan atau materi yang disampaikan adalah secara audio dan visual, seperti melihat gambar, video, dan demonstrasi (Pebrianti D, 2018).

Berdasarkan penelitian yang dilakukan oleh Astrid pada tahun 2016 mengatakan bahwa pengguna internet berdasarkan usia saat ini paling banyak digunakan oleh remaja berusia 12-17 tahun yaitu sebanyak $93 \%$ dan menurut penelitian Rima pada tahun 2018, selain internet remaja menyukai media informasi berupa majalah dengan jumlah sebanyak 12,8\% (Sherlyanita Ak \& Rakhmawati $\mathrm{Na}$, 2016; Ahmad Rs \& Wati Ek, 2018).

Berdasarkan informasi diatas, peneliti tertarik untuk menggabungkan media informasi internet dan majalah menjadi media e-magazine atau elektronik magazine, guna mengetahui pengetahuan remaja putri dengan diberikannya pendidikan kesehatan tentang pencegahan kanker payudara di SMAN Tanjungsari Kecamatan Tanjungsari Kabupaten Sumedang. 


\section{METODOLOGI PENELITIAN}

Jenis penelitian yang dilakukan adalah penelitian kuantitatif dengan metode Quasi Experimental dan pendekatan Pra Eksperimental One Group Pre test-Post test Design. Penelitian ini dilaksanakan di SMAN Tanjungsari pada bulan Juli 2019. Populasi pada penelitian ini adalah remaja putri kelas XI di SMAN Tanjungsari. Penelitian ini menggunakan teknik probability sampling dengan metode pengumpulan sampel proportional sampling dan simple random sampling. Cara melakukan pengambilan sampel pada penelitian ini yaitu dengan mencari terlebih dahulu jumlah siswi dari setiap kelas yang akan di gunakan sebagai responden, kemudian dilakukan pengambilan sampel secara acak atau random dengan menggunakan angka ganjil pada nomor absen setiap kelas. Jumlah sampel dalam penelitian ini adalah 90 orang. Jenis data dalam penelitian ini adalah data kuantitatif yang dikumpulkan menggunakan kuesioner. Data dilakukan uji normalitas terlebih dahulu menggunakan Kolmogorov-Smirnov dengan hasil uji data berdistribusi normal. Analisis data menggunakan analisa univariat disajikan dalam bentuk tabel distribusi frekuensi dan bivariat dengan uji statistik Paired Sample T-Test. Data diolah secara komputerisasi menggunakan program Statistic Package for Social Science (SPSS).

HASIL DAN PEMBAHASAN

Analisis Univariat

Tabel 1.

Distribusi Frekuensi Karakteristik Remaja Putri di SMAN Tanjungsari

\begin{tabular}{lcc}
\hline Karakteristik & Frekuensi (f) & Persentase (\%) \\
\hline Usia & & \\
14-16 tahun & 84 & 93,3 \\
17-19 tahun & 6 & 6,7 \\
Jurusan & & \\
IPA & 64 & 71,1 \\
IPS & 26 & 28,9 \\
\hline \multicolumn{1}{c}{ Jumlah } & 90 & 100 \\
\hline
\end{tabular}

Berdasarkan tabel 1 dapat diketahui bahwa umur responden sebagian besar berumur 14-16 tahun sebesar $93,3 \%$ dan responden dengan jurusan IPA sebesar $71,1 \%$.
Tabel 2.

Distribusi Frekuensi Sumber Informasi tentang Pencegahan Kanker Payudara

\begin{tabular}{lcc}
\hline $\begin{array}{c}\text { Sumber } \\
\text { Informasi }\end{array}$ & $\begin{array}{c}\text { Frekuensi } \\
(\mathrm{f})\end{array}$ & $\begin{array}{c}\text { Persentase } \\
(\%)\end{array}$ \\
\hline Pernah & & \\
Koran & 0 & 0 \\
Majalah & 7 & 7,8 \\
Buku & 5 & 5,6 \\
Brosur & 3 & 3,3 \\
Internet & 37 & 41,1 \\
Televisi & 5 & 5,6 \\
Radio & 0 & 0 \\
Belum Pernah & 33 & 36,7 \\
\hline \multicolumn{1}{c}{ Jumlah } & 90 & 100 \\
\hline
\end{tabular}

Tabel 2 diatas menunjukkan bahwa sebagian besar responden mendapatkan sumber informasi tentang pencegahan kanker payudara melalui internet sebesar $41,1 \%$ dan sebesar $36,7 \%$ belum pernah mendapatkan informasi tentang pencegahan kanker payudara.

Tabel 3.

Distribusi Frekuensi Remaja berdasarkan

Tingkat Pengetahuan Remaja Putri tentang Pencegahan Kanker Payudara

\begin{tabular}{lcccc}
\hline \multirow{3}{*}{ Pengetahuan } & \multicolumn{4}{c}{ Frekuensi (f) } \\
\cline { 2 - 5 } & \multicolumn{2}{c}{ Pre Test } & \multicolumn{3}{c}{ Post } & Test \\
\cline { 2 - 5 } & $\mathrm{f}$ & $\%$ & $\mathrm{f}$ & $\%$ \\
\hline Baik & 59 & 65,5 & 66 & 73,3 \\
Kurang & 31 & 34,4 & 24 & 26,6 \\
\hline \multicolumn{1}{c}{ Jumlah } & 90 & 100 & 90 & 100 \\
\hline
\end{tabular}

Berdasarkan tabel 3 dapat diketahui bahwa tingkat pengetahuan remaja putri dalam kategori baik mengenai pencegahan kanker payudara sebelum dilakukan pendidikan kesehatan sebesar $65,5 \%$ dan setelah dilakukan pendidikan kesehatan sebesar $73,3 \%$.

\section{Analisis Bivariat}

Tabel 4 dibawah menunjukkan rata-rata nilai pengetahuan pre test adalah 23,60 dan post test didapatkan 29,02 . Hasil uji statistik di dapatkan nilai $p<0,05$ yaitu sebesar 0,009 dan nilai $r$ sebesar 0,276 . 
Tabel 4.

Pengaruh E-magazine terhadap Pengetahuan Remaja Putri tentang Pencegahan Kanker Payudara

\begin{tabular}{cccccc}
\hline \multirow{2}{*}{ Pengetahuan } & $\mathrm{N}$ & Median (min-max) & Mean $\pm S D$ & $P$-value & $r$ \\
\cline { 2 - 6 } & 90 & 24,00 & $23,60 \pm 2,369$ & & \\
Pre Test & 90 & 29,00 & $29,02 \pm 1,080$ & 0,009 & 0,276 \\
Post Test & 90 &
\end{tabular}

\section{PEMBAHASAN}

\section{Karakteristik Responden}

Penelitian ini menunjukkan bahwa responden tergolong dalam remaja awal (early adolescent) yang terjadi pada usia 12-15 tahun. Periode remaja merupakan periode yang penting untuk pemberian edukasi yang positif, karena pada masa remaja awal terjadi perubahan yang cepat baik fisik, psikologis dan sosial (Irfaniah R, 2017).

Ciri-ciri remaja umumnya mengalami perubahan seperti perubahan fisik, perkembangan seksual dan perubahan cara berfikir. Bentuk perubahan fisik ialah mulai mengalami pertumbuhan payudara, saat hal ini terjadi baiknya remaja putri mengetahui pemeriksaan payudara sendiri (SADARI) agar dapat mendeteksi kanker payudara sejak dini (Seniorita D, 2017).

Selain perubahan fisik, remaja putri juga mengalami perubahan seksual. Perubahan seksual ini ditandai dengan adanya menstruasi, maka payudara membesar pada umumnya sejak usia 10 tahun dan mulai timbulnya rasa suka terhadap lawan jenis (Amelia R \& Rahman Rta \& Widitria W, 2016).

Perubahan cara berfikir pun di alami oleh remaja, dimana pada saat remaja akan mulai berfikir causative yaitu menyangkut mengenai sebab dan akibat. Selain itu remaja pun akan mulai mampu berfikir untuk mencari alternatif pemecahan masalah dan akibatnya, serta akan mampu menerima informasi dan mencerna informasi tersebut (Irawan E, 2016).

Berdasarkan hasil penelitian ini, responden dengan jurusan IPA di SMAN Tanjungsari memiliki frekuensi terbanyak yaitu sebesar $71,1 \%$ dan IPS sebesar 28,9\%. Program penjurusan di SMA merupakan salah satu upaya untuk menyalurkan minat, bakat dan kemampuan siswa agar mampu dikembangkan secara maksimal. Penjurusan ini dilakukan berdasarkan hasil evaluasi belajar, akumulasi nilai, minat dan bakat siswa di sekolah (Indrianti A \& Sari Pi, 2017).

Menurut hasil penelitian Yuriani (2013) mengenai faktor yang memengaruhi siswa memilih jurusan IPA adalah faktor internal seperti minat, bakat, cita-cita, hasil prestasi dan motivasi belajar. ${ }^{55}$ Adapun hasil penelitian Annisa (2017) mengatakan bahwa siswa memilih jurusan IPS dikarenakan faktor internal yaitu adanya ketertarikan terhadap ilmu pengetahuan sosial. Selain itu juga, terdapat faktor eksternal seperti pengaruh teman sebaya dan pilihan orangtua (Indrianti A \& Sari Pi, 2017).

\section{Sumber Pengetahuan}

Saat ini media informasi melalui internet semakin berkembang dan populer dengan dihadirkannya berbagai fitur yang dapat digunakan. Totok (2016) menyatakan bahwa remaja saat ini merupakan pengguna internet terbanyak, yaitu dalam kelompok usia 15-24 tahun (Abadi Tw \& Sukmawan F \& Utari Da, 2016). Adapun hasil penelitian ini terdapat responden yang belum pernah mendapatkan informasi mengenai pencegahan kanker payudara, hal ini dapat dipengaruhi oleh kurangnya paparan informasi pada individu sehingga tidak mengetahui mengenai kanker payudara dan cara pencegahannya. Sejalan dengan teori menurut Notoatmodjo bahwa informasi akan memberikan pengaruh pada pengetahuan seseorang jika mendapatkan informasi yang baik dari berbagai media (Yuniar Zf \& Qomaruddin Mb, 2019).

Kurangnya inisiatif untuk mencari informasi kesehatan juga dapat memengaruhi hal tersebut, karena berdasarkan penelitian Herlin (2019) mengatakan bahwa remaja perempuan lebih suka menggunakan media sosial untuk menjalin hubungan dengan teman-teman dan menggunakan internet untuk hiburan saja (Kurniawati Hf, 2019). Adapun menurut Luthfiana (2018) mengatakan bahwa remaja menggunakan internet hanya untuk mengerjakan tugas sekolah di bandingkan untuk mencari informasi lainnya (Nur L, 2018).

Kalangan remaja saat ini sudah dapat mengakses internet dengan mudah terutama dalam menggunakan media sosial. Seringkali remaja beranggapan semakin aktif dirinya menggunakan internet dan media sosial akan semakin dianggap keren dan gaul. Hal tersebut sesuai dengan teori bahwa masa remaja adalah masa perkembangan dalam segala hal. Saat ini teknologi internet dan mobile phone semakin maju dan kaum remaja sangat ketergantungan terhadap hal tersebut, sehingga tidak di pungkiri jika remaja dapat 
mengakses berbagai informasi dengan mudah, aktif di media sosial dan berbagi cerita kesehariannya (Putri Wsr \& Nurwati N \& Budiarti M, 2016; Felita P \& Siahaja C \& Wijaya V \& Melisa G \& Chandra M \& Dahesihsari $R, 2016$ ).

Hal ini sejalan dengan hasil penelitian Nuning (2017) mengatakan bahwa media informasi yang paling sering digunakan remaja untuk mencari informasi mengenai kesehatan reproduksi ialah internet, majalah, surat kabar dan buku-buku teks. Hal tersebut di karenakan mudah untuk di cari, mudah untuk di dapatkan dan mudah untuk di pahami berdasarkan kebutuhan informasinya (Kurniasih N, Komariah N, 2017).

\section{Tingkat Pengetahuan Remaja Putri tentang Pencegahan Kanker Payudara}

Pengetahuan merupakan pemahaman yang diperoleh melalui pengamatan panca indera yang sangat penting untuk terbentuknya perilaku seseorang. Menurut Sebayang (2018) hal-hal yang dapat memengaruhi pengetahuan diantaranya pendidikan, media informasi, usia, lingkungan dan pengalaman. Pada penelitian ini saat sebelum diberikan intervensi, responden memiliki pengetahuan yang baik tentang pencegahan kanker payudara. Hal ini dapat dipengaruhi oleh faktor latar belakang pendidikan, dimana tingkat pendidikan SMA sudah cukup tinggi sehingga akan lebih mudah menerima informasi dan memiliki pengetahuan cukup luas (Husna Ph, 2018; Handayani S \& Sudarmiati S, 2012).

Selain faktor pendidikan, faktor lainnya ialah media informasi. Media merupakan bentuk perantara yang berperan untuk menyampaikan informasi dari komunikator kepada komunikan. Informasi tersebut dapat diberikan secara formal atau non formal yang dapat memengaruhi pengetahuan. Pesan atau informasi yang diberikan dapat berupa visual, audio dan audio visual (Fitriansyah F, 2016).

Media informasi yang digunakan pada penelitian ini adalah e-magazine, dimana media tersebut termasuk ke dalam bentuk visual. Media visual merupakan alat yang digunakan dalam proses belajar yang bisa dinikmati oleh panca indera mata. Media visual memiliki beberapa fungsi yaitu, fungsi atensi sebagai daya tarik siswa untuk mengarahkan perhatian dan konsentrasi, fungsi afektif untuk meningkatkan minat baca dan fungsi kognitif untuk mempercepat pemahaman informasi yang terkandung dalam teks dan gambar (Jalinus $\mathrm{N}$ \& Ambiyar A, 2016).

Adapun teori menurut Jerome $S$ Bruner bahwa siswa belajar melalui 3 tahapan, yakni tahap enaktif yaitu melalui benda, tahap ikonik yaitu melalui gambar atau video, dan tahap simbolik yaitu melalui simbol-simbol (Fitriansyah F, 2016). Pada penelitian ini siswi remaja berada pada tahap ikonik, dimana pembelajaran terjadi melalui pemahaman melalui indera penglihatan dengan memahami teks dan gambar.

Faktor yang memengaruhi pengetahuan selanjutnya ialah faktor usia, menurut Notoatmodjo usia memengaruhi terhadap daya tangkap dan pola pikir seseorang. Bertambahnya usia seseorang akan semakin berkembang pula daya tangkap dan pola pikirnya (Amelia R \& Rahman Rta \& Widitria W, 2016).

Berdasarkan hasil post test atau setelah dilakukannya intervensi, di dapatkan hasil peningkatan pengetahuan post test sebesar $8 \%$. Hal ini berarti dapat dikatakan bahwa terdapat pengaruh dari pendidikan kesehatan terhadap pengetahuan responden mengenai pencegahan kanker payudara (Irfaniah R, 2017). Penelitian ini sejalan dengan hasil penelitian Nonik (2018) bahwa terdapat peningkatan nilai pengetahuan antara sebelum dilakukan pendidikan kesehatan kanker payudara dan setelah dilakukan pendidikan kesehatan (Wantini Na, Indrayani N, 2018). Hal ini sejalan dengan tingkatan pengetahuan menurut Notoatmodjo, setelah individu tahu (know) terhadap suatu pesan atau informasi yang di dapatkan, tingkatan selanjutnya ialah memahami (comprehension) terhadap informasi tersebut.

\section{Pengaruh E-magazine terhadap Pengetahuan Remaja Putri tentang Pencegahan Kanker Payudara}

Berdasarkan hasil penelitian diketahui bahwa terdapat perbedaan pengetahuan remaja putri sebelum dan sesudah diberikan media emagazine tentang pencegahan kanker payudara, yang ditunjukkan dengan perbedaan rata-rata pre test sebesar 23,60 meningkat menjadi 29,02.

Karakteristik seorang remaja salah satunya adalah timbul rasa ingin tahu terhadap informasi, biasanya informasi diperoleh dari buku, majalah dan internet. Oleh karena itu majalah dan internet dipilih sebagai media dalam edukasi pencegahan kanker payudara. E-magazine disusun sesuai dengan kebutuhan dan kondisi remaja sehingga materi yang di sajikan di dukung oleh gambar dan tulisan agar lebih menarik dan aplikatif (Safitri Nrd \& Fitranti Dy, 2016).

Menurut Titin (2016) mengatakan bahwa media pembelajaran dapat memperjelas penyampaian materi atau informasi yang disampaikan sehingga dapat meningkatkan 
pemahaman seseorang. Pembelajaran menggunakan sebuah media akan menarik perhatian seseorang untuk lebih ingin tahu terhadap suatu informasi. Dengan demikian media merupakan salah satu unsur penting dalam menentukan keberhasilan kegiatan pembelajaran (Titin T, 2016). ${ }^{26}$

Adapun hasil penelitian Sinta (2017) mengatakan media sosial Whatsapp dan BBM memiliki pengaruh yang signifikan terhadap pengetahuan perawatan masa nifas pada sebelum dan setelah intervensi, dengan nilai $P<0,005$ yaitu 0,000 (Nuryati S \& Yanti D, 2017).

Salah satu faktor yang memengaruhi pengetahuan seseorang adalah media. Media berfungsi untuk memudahkan seseorang dalam mengetahui dan memahami informasi yang di anggap sulit. Peningkatan pengetahuan juga diperoleh dari proses belajar dengan memanfaatkan semua alat indera, dimana $13 \%$ dari pengetahuan diperoleh melalui indera penglihatan dan $35-55 \%$ melalui indera pendengaran dan penglihatan (Safitri Nrd \& Fitranti Dy, 2016).

Berdasarkan kerucut pengalaman Edgar Dale mengatakan bahwa hasil pembelajaran diperoleh melalui pengalaman, salah satunya ialah melalui pembelajaran visual. Pembelajaran visual merupakan pembelajaran yang disajikan oleh tulisan dan gambar, yang dapat memengaruhi $30 \%$ pengetahuan dengan melihat dan membaca sumber informasi yang disajikan (Wanti Asw \& Haris $\mathrm{H}, 2016)$.

Hasil uji Paired Sample T-Test diperoleh nilai $p$-value sebesar 0,009 yang dapat diartikan secara statistik menunjukkan terdapat perbedaan pengetahuan remaja putri sebelum dan sesudah pemberian media e-magazine. Perhitungan korelasi antara media e-magazine dengan tingkat pengetahuan remaja putri tentang pencegahan kanker payudara diperoleh nilai $r$ sebesar 0,276 yang dapat disimpulkan bahwa pendidikan kesehatan dengan media e-magazine memberikan pengaruh yang cukup signifikan terhadap peningkatan pengetahuan remaja putri.

\section{SIMPULAN}

Usia remaja perempuan di SMAN Tanjungsari memiliki rentang usia terbanyak yaitu 14-16 tahun sebesar 93,3\% dan memilih jurusan IPA sebesar $71,1 \%$. Sumber informasi tentang pencegahan kanker payudara yang di dapatkan oleh remaja perempuan di SMAN Tanjungsari paling banyak melalui internet $41,1 \%$ dan majalah $7,8 \%$. Berdasarkan penelitian yang telah dilakukan, terdapat peningkatan skor pengetahuan pencegahan kanker payudara pada remaja putri di SMAN Tanjungsari sebesar $8 \%$ saat sebelum dan sesudah pemberian pendidikan kesehatan dengan media e-magazine. Adapun pengaruh dari media emagazine terhadap pengetahuan remaja putri di SMAN Tanjungsari mengenai pencegahan kanker payudara dengan melihat nilai $p<0,05$ yaitu sebesar 0,009 dan nilai $r$ yang di dapatkan adalah 0,276 .

\section{SARAN}

Sebaiknya remaja putri dapat lebih memahami dan memperhatikan mengenai kesehatan reproduksi sejak dini serta dapat menjadikan e-magazine sebagai referensi dan media pembelajaran untuk mendapatkan informasi kesehatan mengenai pencegahan kanker payudara. Bagi tenaga pendidik (guru) juga dapat bekerja sama dengan tenaga kesehatan dan orangtua agar dapat memberikan pendidikan kesehatan yang tepat pada remaja putri.

\section{DAFTAR PUSTAKA}

Abadi Tw, Sukmawan F, Utari Da. (2016). Media Sosial Dan Pengembangan Hubungan Interpersonal Remaja Di Sidoarjo. Kanal: Jurnal IImu Komunikasi, 2(1):95-106.

Ahmad Rs, Wati Ek. (2018). Efektifitas Pelatihan Peer Educator Terhadap Peningkatan Pengetahuan, Keterampilan Dan Perubahan Skor Body Image Remaja Putri Sman 4 Purwokerto. Jurnal Gizi Dan Pangan Soedirman, 2(1):64-71.

Amelia R, Rahman Rta, Widitria W. (2016). Pengaruh Penyuluhan Kesehatan Reproduksi Terhadap Pengetahuan Dan Sikap Remaja Tentang Pencegahan HIVIAIDS (Abcde) Di Kelas Xi Smk Negeri 3 Banjarmasin. Dinamika Kesehatan Jurnal Kebidanan Dan Keperawatan, 7(1):91-104.

Dinas Kesehatan Provinsi Jawa Barat. (2017). Profil Kesehatan. Bandung: Dinkes.

Dyanti Gar, Suariyani Nlp. (2016). Faktor-Faktor Keterlambatan Penderita Kanker Payudara Dalam Melakukan Pemeriksaan Awal Ke Pelayanan Kesehatan. Jurnal Kesehatan Masyarakat, 11(2):276-84.

Felita P, Siahaja C, Wijaya V, Melisa G, Chandra M, Dahesihsari R. (2016). Pemakaian Media Sosial Dan Self Concept Pada Remaja. Manasa-Old, 5(1):30-41.

Fitriansyah F. (2016). Pemanfaatan Media Pembelajaran (Gadget) Untuk Memotivasi Belajar Siswa Sd. Cakrawala-Jurnal Humaniora, 16(1). 
Handayani S, Sudarmiati S. (2012). Pengetahuan Remaja Putri Tentang Cara Melakukan Sadari. Jurnal Keperawatan Diponegoro, 1(1):93-100.

Husna Ph. (2018). Peningkatan Pengetahuan Remaja Putri Tentang Pemeriksaan Payudara Sendiri (Sadari) Melalui Pendidikan Kesehatan Di Smk N 1 Wonogiri. Jurnal Keperawatan Gsh, 5(2).

Indrianti A, Sari Pi. (2017). Analisis Faktor-Faktor Yang Memengaruhi Minat Siswa Memilih Jurusan Ips Se-Kecamatan Pasar Sungai Penuh. Sjee: Scientific Journals Of Economic Education, 1(1):1-10.

Irawan E. (2016). Gambaran Pengetahuan Remaja Tentang Kesehatan Reproduksi Di Desa Kertajaya. Jurnal Keperawatan Bsi, 4(1).

Irfaniah R. (2017). Pengaruh Penyuluhan Kesehatan Tentang Pemeriksaan Payudara Sendiri (Sadari) Terhadap Tingkat Pengetahuan Sadari Di Smp Islam Haruniyah Kota Pontianak Tahun 2016. Jurnal Proners, 3(1).

Jalinus N, Ambiyar A. (2016). Media Dan Sumber Pembelajaran, 6.

Kementrian Kesehatan Ri. (2014). Hilangkan Mitos Tentang Kanker. Kemenkes Ri. Diunduh Dari:

http://www.depkes.go.id/article/print/2014070 70001/hilangkan-mitos-tentang-kanker.html.

Kurniasih N, Komariah N. (2017). Peta Pencarian Informasi Kesehatan Reproduksi Remaja Kota Bandung Berdasarkan Jenis Kelamin, Latar Belakang Pendidikan, Status Sosial Dan Ekonomi.

Kurniawati Hf. (2019). Gambaran Penggunaan Internet Dalam Pencarian Informasi Tentang Hiv Dan Aids Pada Remaja. Jurnal Kebidanan, 8(1):27-37.

Nur L. (2018). Gambaran Penggunaan Internet Dalam Mencari Informasi Kesehatan Pada Siswa Sekolah Menengah Pertama (Smp) X. Jurnal Promkes, 6(2):188-200.

Nuryati S, Yanti D. (2017). Efektifitas Penggunaan Media Sosial Terhadap Peningkatan Pengetahuan Perawatan Nifas Dan Kepatuhan Kunjungan Ulang Pada Ibu Nifas Di Kota Bogor. Jurnal Bidan "Midwife Journal, 3(1).

Pebrianti D. (2018). Evaluasi Pengetahuan Sebelum Dan Sesudah Penyuluhan Tentang Kanker Payudara Dan Praktik Sadari Di
Madrasah Aliyah Hidayatul Muslimin 2 Kecamatan Sungai Raya Kabupaten Kubu Raya. Jurnal Kebidanan, 6(2).

Putri Wsr, Nurwati N, Budiarti M. (2016). Pengaruh Media Sosial Terhadap Perilaku Remaja. Prosiding Penelitian Dan Pengabdian Kepada Masyarakat, 3(1).

Safitri Nrd, Fitranti Dy. (2016). Pengaruh Edukasi Gizi Dengan Ceramah Dan Booklet Terhadap Peningkatan Pengetahuan Dan Sikap Gizi Remaja Overweight: Universitas Diponegoro.

Seniorita D. (2017). Pengaruh Pendidikan Kesehatan Tentang Sadari Terhadap Pengetahuan Dan Sikap Remaja Putri Dalam Upaya Deteksi Dini Kanker Payudara Di Sma Yaspend Paba Tahun 2017. Jurnal Riset Hesti Medan Akper Kesdam //Bb Medan, 2(2):93-104.

Sherlyanita Ak, Rakhmawati Na. (2016). Pengaruh Dan Pola Aktivitas Penggunaan Internet Serta Media Sosial Pada Siswa Smpn 52 Surabaya. Journal Of Information Systems Engineering And Business Intelligence, 2(1):17-22.

Sinaga Cf, Ardayani T. (2016). Hubungan Pengetahuan Dan Sikap Remaja Putri Tentang Deteksi Dini Kanker Payudara Melalui Periksa Payudara Sendiri Di Sma Pasundan 8 Bandung Tahun 2016. Kartika: Jurnal IImiah Farmasi, 4(1):16-9.

Titin T. (2016). Penyusunan Perangkat Pembelajaran Pada Materi Ruang Lingkup Biologi Kelas X Sma. Jurnal Pendidikan Matematika Dan Ipa, 7(1):45-56.

Wanti Asw, Haris H. (2016). Peranan Media Gambar (Visual) Dalam Meningkatkan Konsentrasi Belajar Siswa Pada Mata Pelajaran Pkn Di Smpn 1 Sungguminasa Kabupaten Gowa. Jurnal Tomalebbi, 2(2):2934.

Wantini Na, Indrayani N. (2018). Dampak Intervensi Pendidikan Kesehatan Kanker Payudara Pada Remaja Putri Di Sma Negeri 1 Turi, Sleman, Diy. Journal Of Health Education, 3(1):29-36.

Yuniar Zf, Qomaruddin Mb. (2019). Hubungan Antara Faktor Personal Dengan Perilaku Pemeriksaan Payudara Sendiri (Sadari) Pada Mahasiswi S1 Kesehatan Masyarakat Universitas Airlangga. Jurnal Keperawatan Muhammadiyah, 4(2). 